\title{
On the medical history of xanthines and other remedies for asthma: a tribute to HH Salter
}

\author{
CARL GA PERSSON
} From the Department of Clinical Pharmacology, University Hospital of Lund, and AB Draco (Astra Group),
Research and Development Department, Pharmacological Laboratory, Lund, Sweden

Credit for the introduction of xanthines into the treatment of asthma has usually been attributed to Herrmann and to Greene, and their respective colleagues, who showed the appreciable effect of intravenous theophylline in $1937 . .^{12}$ Two essays ${ }^{34}$ entirely devoted to the medical history of xanthines in asthma have, however, contained the suggestion that credit might also go to Macht and Ting ${ }^{5}$ for in vitro pharmacological work and to Hirsch $^{6}$ for clinical experimental work. These reports from late 1921 and early 1922 dealt with different xanthine derivatives, including theophylline and theobromine.

In an earlier review of the pharmacology of asthma - I set out to find even earlier examples of therapeutic experience with the xanthines. ${ }^{7}$ Beverages such as coffee and tea containing considerable amounts of caffeine (which is very similar to theophylline in its actions) have been consumed widely since ancient times and some note of their effects on asthmatic symptoms ought to have found its way into medical writings. Surprisingly, there was nothing substantial on this subject in pharmacognostic publications or in the 20th century bibliography dealing with xanthines in asthma. A French thesis from 1890 by Parisot, ${ }^{8}$ however, dealt with effects of caffeine, for example, on exercise induced dyspnoea and its interaction with alcohol (Chartreuse liquor). In the list of references Parisot included the following under the letter $\mathrm{H}$ : "Hyde-Salter.-Mode d'action du café dans l'asthme. Edinb. med. Journ., 1859." The finding and reading of Dr Salter's report ${ }^{9}$ on the value of strong black coffee in asthma was a very exciting experience. ${ }^{7}$ It seems entirely appropriate to put Salter in front of those previously credited with the discovery of the usefulness of xanthines in bronchial asthma. ${ }^{7}$ Since its rediscovery the Salter reference has been cited only a few times and then merely as anecdotal information.

Address for reprint requests: Dr Carl GA Persson, AB Draco, Box 1707, S221 01 Lund, Sweden.
In this essay I will attempt to examine the relative merits of Salter's observations on coffee and at the same time review some of the insights into asthma and its remedies that he put forward.

\section{Salter and asthma}

Henry Hyde Salter, MD FRCP (1823-1871), as is stated in one of the obituaries, ${ }^{10}$ "had himself been a sufferer from asthma, and early in his career he turned his attention specially to chest disorders, and began to collect materials for a work on his own malady. His work on asthma was published in 1860 , and was generally recognised as the best authority upon the subject, rapidly passing into a second edition." Both editions of the book "On asthma, its pathology and treatment" were produced also by American publishers. ${ }^{11-14}$

His book was probably not so well received by everyone. Salter had an unorthodox, open minded approach to his subject, frequently tearing to pieces the views and writings of others. For example, Bree's theory that asthma is "merely an extraordinary effort to get rid of some peccant and irritating matter existing in the air-tubes" is disposed of in a few paragraphs, ending with: "The fact is, Dr Bree mistook the effect for the cause." 13

Salter is modest when presenting his controversial view that it is deep inspiration and not prolonged expiration that "overcomes and breaks through the contracted state of the air-tubes": "At any rate, I can only say that I have never observed what Laennec and Williams affirm, and have frequently seen what I have above described; and respect for authority however high, should never be pushed to the concession of anything positively observed."

Salter is obviously unhappy with the classification of asthma. "I must be pardoned for not taking up the reader's time in enumerating the different classifications of asthma adopted by different writers. 
The chief cause of their failure has been, I believe, a want of simple reading of nature, its place being supplied by an unquestioning inheritance and adoption of received notions. It seems to me to be a subject in which authors have done more in the way of reading each other's books than scrutinising their own patients." 13

These examples should serve as a useful introduction to the present discussion as they illustrate the originality of the observations made by Salter and the value he placed on them rather than on accepted opinion.

Many parts of Salter's book may still be regarded as authoritative. Permutt ${ }^{15}$ states that he "know[s] of no better description of the role of excessive irritability and the nervous system than that of Salter." He quotes the following: "In what, then, does the peculiarity of the asthmatic essentially consist? Manifestly, it is a morbid proclivity of the musculonervous system of his bronchial tubes to be thrown into a state of activity; the stimulus may be either immediately or remotely applied, but in either case would not normally be attended by any such result. There is no peculiarity in the stimulus, the air breathed is the same to the asthmatic and the nonasthmatic, the ipecacuan powder, the hay effluvium, is the same in both; nor, probably, is there any peculiarity in the irritability of the bronchial muscle; the peculiarity is confined to the link that connects these two-the nervous system, and consists in its perverted sensibility, in its receiving and transmittıng on to the muscle, as a stimulus to contraction, that of which it should take no cognizance... it is clear that the vice in asthma consists, not in the production of any special irritant, but in the irritability of the part irritated."13

Salter does not disclose directly that he himself suffers from asthma. His intimate knowledge of the disease, of course, suggests this fact and so do some inserted remarks. After describing and analysing with enviable logic and clarity the phenomena of the asthmatic paroxysm-its premonitory and initial symptoms; its relation to dyspeptic symptoms, posture, etc; and its preferential occurrence in the early morning, together with all of the auscultatory signs and their meaning, and more-he sees the need to add: "Such, very feebly described, and with too much detail to make a telling picture, is a fit of asthma. To be fairly imagined it should be witnessed - to be fully appreciated it should be experienced." ${ }^{13}$ (In the appendix of his book it is evident that the detailed narration of case number $\mathbf{X}$ is about Salter himself.)

To explain the hyperresponsiveness of the asthmatic airway Salter focused both on neural mechanisms and on inflammatory vascular changes. In particular, of bronchitic asthma he has this to say:
"The organic disease that gives rise to bronchial spasm is such as immediately affects the vascular condition of the bronchial mucous membrane-the inflammation or congestion of the mucous surface appears to be the stimulus that, through the nerves of the air-tubes, excites the muscular wall to contract" and "... a good deal of the dyspnea ... is due not only to the mucous membrane being tumid from inflammation and so narrowing the calibre of the tubes, but to active contraction from the irritation and exalted sensibility that the inflammation gives rise to." 13

This reasoning agrees nicely with recent views implying a major role of airway oedema and other inflammatory mechanisms in asthma. ${ }^{1617}$ Salter described asthma induced specifically by inhalation of cold air. He himself experienced exercise as an exciting cause of asthma but noted the benefit induced by prolonged bodily exertion in several cases of asthma, proving to him "the compatibility of asthma with perfect organic health of the lung" (distinguishing it from dyspnoea caused by bronchitis, emphysema, and cardiovascular diseases). $\mathrm{He}$ described in detail hay asthma and asthma caused by the domestic cat (see in particular the narration of case $\mathrm{X}^{13}$ ). He discussed a prodromal itching under the chin in asthma, ${ }^{13}$ which has recently been rediscovered. ${ }^{18} \mathrm{He}$ made many other salient analyses of the asthmatic condition, some of which have been well accounted for by Neale. ${ }^{19}$ Salter's writings illustrate repeatedly the lasting value of intelligent and open minded reading of nature.

\section{Salter on antimuscarinics}

In his chapter on treatment of asthma with "sedatives" Salter takes a stand against the use of opium in asthma, emphasising that it may worsen the disease both theoretically and in practice. He then proceeds tò discuss stramonium (dried leaf and flowering or fruiting tops of Datura stramonium containing appreciable amounts of atropine): "The smoking of the datura as a remedy for asthma was introduced in 1802, from India, by General Gent, and soon obtained, as new remedies are apt to, the reputation of being specific and infallible;--everybody with any shortness of breathing was smoking stramonium. Its use, however, has illustrated the general inapplicability of any one remedy to all cases of a disease, and the special caprice of asthma; and time has shaken it into its proper place, and assigned it its true worth:- that its original reputation greatly exaggerated its merits, but that it has undoubted though very unequal value, and will probably always maintain its place amongst the real remedies of asthma."13

In 1869 , Salter $^{20}$ extended his discussion on the 
nervous nature of asthma to include this remedy, making the statement: "If I were to express what appears to me to be the peculiar excellence of belladonna as a sedative in asthma I should say it consisted in its power of diminishing reflex irritability." This prescient description of antimuscarinic drugs in asthma may compete in accuracy with his statements on coffee $^{9}$ (see below).

\section{Salter and "sympathomimetics"}

An equally striking observation by Salter, which has also been little noticed, concerns his apparent prediction of the usefulness of sympathomimetic drugs in asthma. Being well aware of the fact that mental emotion could have the effect of both inducing and relieving asthma, Salter distinguished between immediate and remote effects of "any strong and sudden passion... the immediate effect of emotion is always to cut short asthmatic spasm, if it exists, by a sort of nervous revulsion; whereas its tendency to induce it is remote, and only shown after some time." ${ }^{13}$ Already in 1859 Salter $^{9}$ reported on cases of sudden alarm, like fear, fright, or surprise, but also of pleasant excitements thus: "The cure of asthma by violent emotions is more sudden and complete than by any other remedy whatever... I think, too, that mental emotion acts, if I may so express it, as a nervous derivative." The events described by Salter were clearly associated with sympathoadrenal activation, thus illustrating the antiasthmatic action of adrenaline. (It has now been confirmed that physiological levels of adrenaline in plasma influence airway calibre in patients with asthma. ${ }^{2122}$ ) Interestingly, in 1900, when adrenal extracts had just been shown to possess vasoconstrictor properties, Solis-Cohen ${ }^{23}$ successfully (and for the first time?) examined the effect of this substance in asthmatic individuals, in whom, according to him, symptoms were associated with "vasomotor ataxia, of the relaxing variety." Doing the right thing for the wrong reason is not uncommon in science. Seven years later, $\mathrm{Kahn}^{24}$ showed that adrenaline had relaxant effects on tracheal tone.

The further development of antiasthmatic sympathomimetics may illustrate another not uncommon relationship between drugs and progress in research. Isoprenaline was described by Konzett ${ }^{25}$ in 1941 as a potent catecholamine sharing some effects, including bronchodilation, with adrenaline. Seven years later isoprenaline became a most important tool in the hands of Ahlquist, ${ }^{26}$ who was able to partition sympathomimetic effects into $\alpha$ and $\beta$ receptor mediated actions. Likewise the selective $\beta_{2}$ receptor agonists terbutaline and salbutamol were synthesised and characterised before the concept of $\beta_{1}$ and $\beta_{2}$ receptors had been introduced by Lands and coworkers ${ }^{27}$ in 1967. Research on $\beta$ adrenoceptors has since then increased tremendously. Huge numbers of publications on receptor binding and activation, and the ensuing subcellular events, have accumulated. Approaches based on these theoretical receptor models have not, however, as yet brought new antiasthmatic drugs on to the therapeutic scene.

\section{Effect of coffee}

The first paragraph in Salter's report of $1859^{\circ}$ is as follows: "One of the commonest and best-reputed remedies of asthma, one that is almost sure to have been tried in any case that may come under our observation, and one that in many cases is more efficacious than any other, is strong coffee." This statement by an expert on asthma must be considered important. Salter does not claim that he is the first to discover the effect of coffee in asthma. On the other hand, in his extensive reading of publications on asthma he has obviously not found a relevant account of the value of coffee, because he gives no reference. A year later Foucart ${ }^{28}$ described two cases in which large doses of coffee were a unique and successful treatment of asthma, and noticed that previously Musgrave, Bree, Pringle, Percival, Laennec, Trousseau, and Floyer had mentioned coffee in relation to asthma. In particular, an account by Floyer ought to be taken seriously because he, like Salter, suffered from asthma. (The combination of having the disease and being a professional expert on asthma seems to be very important for the discovery of antiasthma drugs even in modern times. ${ }^{29}$ ) Foucart refers to a man who himself had suffered from asthma for 50 years and who had written a highly esteemed treatise on asthma. From this description it can be deduced that he was referring to Sir John Floyer MD-see ref 30. Floyer's famous book was.called $A$ Treatise of the Asthma ${ }^{31}$ and was first published in 1698 . In this book of some 200 pages he credits Galen, Hippocrates, and many old writers and specifies hundreds of drinks suitable for the asthmatic (decoctions, infusions, syrups, juleps, elixirs, etc.). Coffee, however, is mentioned only once and is certainly not praised in this book (third edition, 1745, p 78): "All hot Liquors, as Coffees, Teas; of Cephalick Herbs, as Sage etc. or Stomachic, as Buckbean, which is a Centaury, I have tried, but find none so good as Toast and Water." In a chapter entitled "The Regimen in the Asthma," which is contained in his book The Galenic Art of Preserving Old Men's Healths, ${ }^{32}$ Floyer also mentions coffee but merely says, "Use coffee and tea three hours after dinner to help digestion." If he is not mistaken Foucart must have seen some other work by Floyer where he may contradict his statement above.

Two thirds of Salter's patients were reported to 
benefit from intake of coffee. This rate of success may be related to the fact that Salter was concerned with the dosage and time of administration of coffee. "It cannot be given too strong..." If administered in too "much bulk .... its effect is less rapid - and it oppressively distends the stomach .... It should be given on an empty stomach." These pieces of advice fit well with pharmacokinetic teaching on how to achieve rapidly high blood levels of xanthines. Furthermore, Salter indicated a dose of "two breakfast cups of strong coffee," which ought to contain an amount of caffeine similar to that which now has been confirmed to be effective in asthma. ${ }^{33}$

Admittedly, Salter ${ }^{9}$ may have been wrong in his discussion of the nature of the coffee remedy. He was well aware of the fact that symptoms of asthma are worst in the early morning after a few hours of sleep. He had noticed that sudden alarm or other extreme excitements could instantaneously inhibit asthma symptoms. It was therefore natural for him to connect the stimulant actions on the central nervous system of coffee with its beneficial effects in asthma: "Now, if the suspension of the will, or its depression, favours the production of excitomotory phenomena, and thus favours the development of asthma, is it unreasonable to suppose that its exaltation should prevent or cure it?"

Today, sympathomimetics and xanthines are established as bronchodilators. There is, however, a growing discussion of the anti-inflammatory potential of these drugs ${ }^{3435}$ and it is noteworthy that some workers again place beneficial effects of xanthines outside the lung, now inferring that these drugs importantly decrease fatigue of the respiratory muscles. ${ }^{36} \mathrm{~A}$ drug development, similar to that already established with sympathomimetics (see above), may take place also with xanthines. In support of this possibility, a novel antiasthmatic xanthine derivative, with increased specificity (compared with caffeine and theophylline) concerning the clinical effects and cellular mechanisms of action, has recently been described. ${ }^{3437}$ As with the $\beta$ receptor agonists, this xanthine derivative emerged as a phenomenon and is now a challenge to established concepts of how xanthines may work at the cellular level. ${ }^{\text {3437 }}$

The pharmacological ingenuity of Hyde Salter should be emphasised. In retrospect, his shrewd observations would have been a sound basis for the development of today's major antiasthma drugsxanthines, sympathomimetics, and antimuscarinics.

Macht and Ting (1921): problems with the structureactivity relationships of xanthines?

According to May, ${ }^{3}$ Macht and Ting ${ }^{5}$ deserve priority and considerable credit for demonstrating in vitro the antispasmodic action of theophylline on smooth muscle from bronchi. By 1921, however, different workers had repeatedly shown that caffeine relaxes isolated airway preparations. ${ }^{73839}$ Furthermore, a closer scrutiny of the work by Macht and Ting reveals some astonishing findings. They found little relaxation in response to caffeine (an effect noted as important by $\mathrm{May}^{3}$ ), stating that the dimethylxanthines theobromine and theophylline produced much greater bronchodilation than caffeine. (Macht and Ting ${ }^{5}$ actually give the wrong chemical structures, mistaking theobromine for theophylline; but that matters little since they could not distinguish between the effects of these two dimethylxanthines.) Furthermore, they reported that xanthine itself was the most potent relaxant of the xanthines studied.

Recent quantitative in vitro findings have, however, shown otherwise theophylline being only marginally more potent than caffeine, and about twice as potent as theobromine. All of these methylxanthines produce the same large maximum relaxation of isolated airway smooth muscle, their dose-response curves have the same shape, and all are considerably more potent than xanthine itself. ${ }^{40}$ The principal achievement of Macht and Ting $^{5}$ was thus the confirmation that xanthines relax bronchial smooth muscle in vitro. Their data on different xanthines were misleading and could not have served as a basis for the selection of a particular xanthine derivative for clinical use. Instead, credit for the first demonstration of the bronchial relaxant properties (in vitro and in animal models) of xanthines should go to Trendelenburg ${ }^{38}$ and $\mathrm{Pal}^{39}$ who published their findings with caffeine in 1912.

Macht and Ting are in good company. Until recent years many misconceptions about the structure and activity of xanthines have flourished in pharmacomedical communications and textbooks-for example, salts of theophylline have not been distinguished from its chemical derivatives. ${ }^{347}$ The relative ignorance on this subject probably contributes to the fact that the value of theophylline in asthma was quite controversial only a decade ago.

\section{Hirsch (1922) ${ }^{6}$ : bronchodilation in vitro and in vivo by a combination of dimethylxanthines}

Prompted in part by the fact that Trendelenburg and Pal had shown caffeine to have bronchorelaxant properties, Hirsch ${ }^{6}$ set out to examine the bronchodilator effects of xanthine derivatives in three asthmatic subjects. For this purpose a suppository consisting of two thirds theophylline and one third theobromine was available to him. His case records indicate that treatment was successful and that he went on to examine its effects in isolated bronchi 
obtained from the cow. Using the technique described by Trendelenburg, ${ }^{38}$ he showed that the combination of theophylline and theobromine produced relaxation-a nice example of combining clinical experimental work with pharmacological experiments in animals. Before this, Allard ${ }^{41}$ had been concerned about the frequency of seizures occurring after administration of theophylline, then in use as a diuretic, and had published both clinical case reports illustrating this serious side effect and the results of animal experiments showing that increasing doses of theophylline eventually evoked seizures.

Although $\mathrm{Hirsch}^{6}$ in his report clearly advocated the use of xanthines in asthma, this was not followed by a striking increase in this use of theophylline. This may be because Hirsch did not specifically mention theophylline in his summary and conclusions, but instead devoted a full paragraph to the suggestion that theobromine should be valued not only as an analeptic and diuretic drug but also as a bronchodilator. The fact that the amount of theobromine given was only half that of theophylline, together with the potency relationship that exists between these two xanthines, strongly suggests that theobromine was responsible only for a minor part of the bronchodilation reported by Hirsch. ${ }^{6}$ Nevertheless, Hirsch obviously made an important contribution, and both he and those workers who showed the clinical efficacy of intravenous theophylline in many asthmatic patients in the 1930s have received due credit for their work in essays by May $^{3}$ and by SchultzeWerninghauz and Meijer-Sydow. ${ }^{4}$ None of the twentieth century reports by Herrmann et al, ${ }^{1}$ Greene et $a{ }^{2}{ }^{2}$ Hirsch, ${ }^{6}$ Macht and Ting, ${ }^{5} \mathrm{Pal}^{39}$ and Trendelenburg ${ }^{38}$ referred to Salter, which probably explains why his writings on coffee were neglected for such a long time.

\section{Conclusion}

Significantly, Salter with his deep knowledge of asthma singled out the value not only of coffee but also of belladonna and of "violent emotions" from the very complex therapeutic armamentarium of the nineteenth century. It is sad to learn that Salter had to surrender, in the midst of his career, to the disease on which he was such an expert. I quote from one of the obituaries $^{42}$ : "During the last four years that strangely capricious malady, asthma, which had afflicted him in childhood and adolescence, and then left him for many years, returned with terrible force...."

I thank Ingegerd Källén for typing the manuscript and the librarians Marianne Persson and Birgitta Ovesson for their kind assistance.

\section{References}

1 Herrmann GR, Aynesworth MB, Martin J. Successful treatment of persistent extreme dyspnea, "status asthmaticus"- use of theophylline ethylene diamine (aminophylline USP) intravenously. Lab Clin Med 1937; 23:135-48.

2 Greene JA, Paul WD, Faller AE. The action of theophylline with ethylene diamine on intrathecal and venous pressures in cardiac failure and on bronchial obstruction in cardiac failure and in bronchial asthma. JAMA 1937;109:1712-15.

3 May CD. History of the introduction of theophylline into the treatment of asthma. Clin Allergy 1974;4:211-7.

4 Schultze-Werninghaus G, Meijer-Sydow J. The clinical and pharmacological history of theophylline: first report on the bronchospasmolytic action in man by SR Hirsch in Frankfurt (Main). Clin Allergy 1982;12:211-5.

5 Macht DI, Ting GC. A study of antispasmodic drugs on the bronchus. Pharmacol Exp Ther 1921;18:373-98.

6 Hirsch S. Klinischer und Experimenteller Beitrag zur Krampflösenden Wirkung der Purinderivate. Wochenschr 1922;1:615-8.

7 Persson CGA. Some pharmacological aspects on xanthines in asthma. Eur $J$ Respir Dis 1980;61, suppl 109:7-16.

8 Parisot M. L'action de la caféine. In: Steinheil G, ed. Thèse de Paris. Paris: 1890:1-112.

9 Salter $\mathrm{H}$. On some points in the treatment and clinical history of asthma. Edinburgh Medical Journal 1859;4:1109-15.

10 Anonymous. Salter HH [obituary]. Lancet 1871;ii:415-6.

11 Salter HH. On asthma: its pathology and treatment. London: Churchill, 1860:372.

12 Salter HH. On asthma: its pathology and treatment. Philadelphia: Blanchard and Lea, 1864:260.

13 Salter HH. On asthma: its pathology and treatment. 2nd ed. London: Churchill, 1868:464.

14 Salter HH. On asthma: its pathology and treatment. New York: Wood and Company, 1882:284.

15 Permutt S. Irritability and allergy: the neuron and the mast cell. Am Rev Respir Dis 1980;122:187-9.

16 Dunnill MS. The morphology of airways in asthma. In: Stein M, ed. New directions in asthma. Park Ridge, USA: American College of Chest Physicians, 1975:213-22.

17 Persson CGA, Svensjö E. Airway hyperreactivity and microvascular permeability to large molecules. Eur $J$ Respir Dis 1983;64, suppl 131:183-214.

18 Derbes VJ. Prodromal itching in asthma. Lancet 1984;ii:822.

19 Neale AV. Some thoughts and experiments on respiration and on asthma, with special reference to Henry Hyde Salter. Med Hist 1963;7:247-57.

20 Salter $H$. On the treatment of asthma by belladonna. Lancet 1869:152-3.

21 Barnes P, Fitzgerald G, Brown M, Dollery C. Nocturnal asthma and changes in circulating epinephrine, histamine and cortisol. $N$ Engl J Med 1980;303:263-7.

22 Berkin KE, Inglis GC, Ball SG, Thomson NC. Role of physiological concentrations of catecholamines in the control of airway calibre in asthmatic patients [abstract]. Thorax 1984;39:697.

23 Solis-Cohen $\mathrm{S}$. The use of adrenal substance in the treatment of asthma. JAMA 1900;34:1164-6.

24 Kahn RH. Zur Physiologie der Trachea. Arch Physiol 1907:398-426. 
25 Konzett $\dot{H}$. Neue broncholytische, hochwirksame Körper der Adrenalinreihe. N S Arch Exp Pathol Pharmakol 1941;197:27-32.

26 Ahlquist RP. A study of the adrenotropic receptors. Am J Physiol 1948;153:586-99.

27 Lands AM, Arnold A, McAuliff JP, Luduena FP, Brown TG jun. Differentiation of receptor systems activated by sympathomimetic amines. Nature 1967;214:597-9.

28 Foucart A. Du café dans le traitment de l'asthme nerveux ou essentiel. La France Médicale et Pharmaceutique 1860:300-1.

29 Altounyan RE. Review of clinical activity and mode of action of sodium cromoglycate. Clin Allergy 1980;10, suppl:481-9.

30 Sakula A. Sir John Floyer's $A$ treatise of the asthma (1698). Thorax 1984;39:248-54.

31 Floyer J. A treatise of the asthma. London: R Wilkins, 1698.

32 Floyer J. Medicina Gerocomica or, The Galenic Art of Preserving Old Men's Healths. London: J Isted, 1725.

33 Becker AB, Simons KJ, Gillespie CA, Simons FER. The bronchodilator effects and pharmacokinetics of caffeine in asthma. $N$ Engl J Med 1984;310:183-6.

34 Persson CGA. The profile of action of enprofylline, or why adenosine antagonism seems less desirable with xanthine antiasthmatics. In: Morley J, Rainsford KD, eds.
Pharmacology of asthma. Basel: Birkhauser, 1983: 115-29.

35 Persson CGA, Erjefält I, Grega GJ, Svensjö E. The role of $\beta$-receptor agonists in the inhibition of pulmonary edema. In: Lung microvascular injury. Malik A, Staub N, eds. Ann N Y Acad Sci 1982;384:544-57.

36 Aubier M, De Troyer A, Sampson M, Macklem PT, Roussos C. Aminophylline improves diaphragmatic contractility. N Engl J Med 1981;305:249-52.

37 Persson CGA. Xanthines for asthma-present status. Trends Pharmacol Sci 1982;3:312-3.

38 Trendelenburg P. Physiologische und pharmakologische Untersuchungen an der isolierten Bronkialmuskulatur. Arch Exp Pathol Pharmakol 1912;69:79-107.

$39 \mathrm{Pal}$ J. Ueber die Wirkung des Koffeins auf die Bronkien und die Atmung. Dische Med Wochenschr 1912;38: 1774-6.

40 Karlsson JA, Kjellin G, Persson CGA. Effects on tracheal smooth muscle of adenosine and methylxanthines, and their interaction. $J$ Pharmacol Pharmacol 1982;34:788-93.

41 Allard E. Uber Theocinvergiftung. Arch Klin Med 1904;80:510-9.

42 Anonymous. Salter HH [obituary]. Medical Times and Gazette 1871;2:363-4. 